\title{
Assesment of New Analytical Method for Solving the Foam Drainage Equation
}

\author{
Ali Nikkar \\ Faculty of Civil Engineering, University of Tabriz, Tabriz 5166116471, Iran \\ Correspondence should be addressed to Ali Nikkar; ali.nikkar@yahoo.com
}

Received 29 August 2013; Accepted 5 December 2013; Published 4 February 2014

Academic Editors: S. N. U. A. Kirmani and J. Sun

Copyright ( 2014 Ali Nikkar. This is an open access article distributed under the Creative Commons Attribution License, which permits unrestricted use, distribution, and reproduction in any medium, provided the original work is properly cited.

\begin{abstract}
The drainage of liquid foams involves the interplay of gravity, surface tension, and viscous forces. Foaming occurs in many distillation and absorption processes. In this study, a new reliable technique is used to handle the foam drainage equation. This new method resulted from VIM by a simple modification, that is, variational iteration method-II (VIM-II). It has been shown that the VIM-II is a powerful technique in obtaining accurate solutions that cannot be given otherwise by perturbation and other methods. The accuracy and convergence of the method are also investigated and compared with other methods. The results showed that there are good agreements between the results.
\end{abstract}

\section{Introduction}

Foams $[1,2]$ are a prime example of a multiphase "soft condensed matter" system. They have important applications in the food and chemical industries, firefighting, mineral processing, and structural material science [3], and their properties are of subject of intensive studies from both practical and scientific points of view [4]. Foams are common in personal care products such as creams and lotions, and foams often occur, even when not desired, during cleaning (clothes, dishes, scrubbing) and dispensing processes (cf. [5]). Less obviously they appear in acoustic cladding, lightweight mechanical components, and impact absorbing parts on cars, heat exchangers, and textured wallpapers (incorporated as foaming inks) and even have an analogy in cosmology. History connects foams with a number of eminent scientists, and foams continue to excite imaginations [6]. Although there are now many applications of polymeric foams [7] and more recently metallic foams, which are foams made out of metals such as aluminum [8]. In addition, industrial applications of polymeric foams and porous metals include their use for structural purposes and as heat exchange media analogous to common "finned" structures [9].

Recent research in foams and emulsions has been centered on three topics which are often treated separately but are in fact interdependent: drainage, coarsening, and rheology; see Figure 1. We focus here on a quantitative description of the coupling of drainage and coarsening.

The flow of liquid relative to the bubbles is called drainage. Drainage plays an important role in foam stability: indeed, when foam dries, its structure becomes more fragile; the liquid films between adjacent bubbles being thinner, then can break, leading to foam collapse. In the case of aqueous foams, surfactant is added into water and it adsorbs at the surface of the films, protecting them against rupture (cf. [10]).

Foam drainage is the flow of liquid through channels (Plateau borders) and nodes (intersections of four channels) between the bubbles, driven by gravity and capillarity [11-13].

The foam drainage equation models the dynamics of the liquid volume in the foam on length scales larger than the bubble size. Generally drainage is driven by gravity and/or capillary (surface tension) forces and is resisted by viscous forces (cf. [5]).

Recent theoretical studies by Verbist and Weaire describe the main features of both free drainage [14, 15], where liquid drains out of a foam due to gravity, and forced drainage [16], where liquid is introduced to the top of a column of. Forced foam drainage may well be the best prototype for certain general phenomena described by nonlinear differential equations, particularly the type of solitary wave which is most 


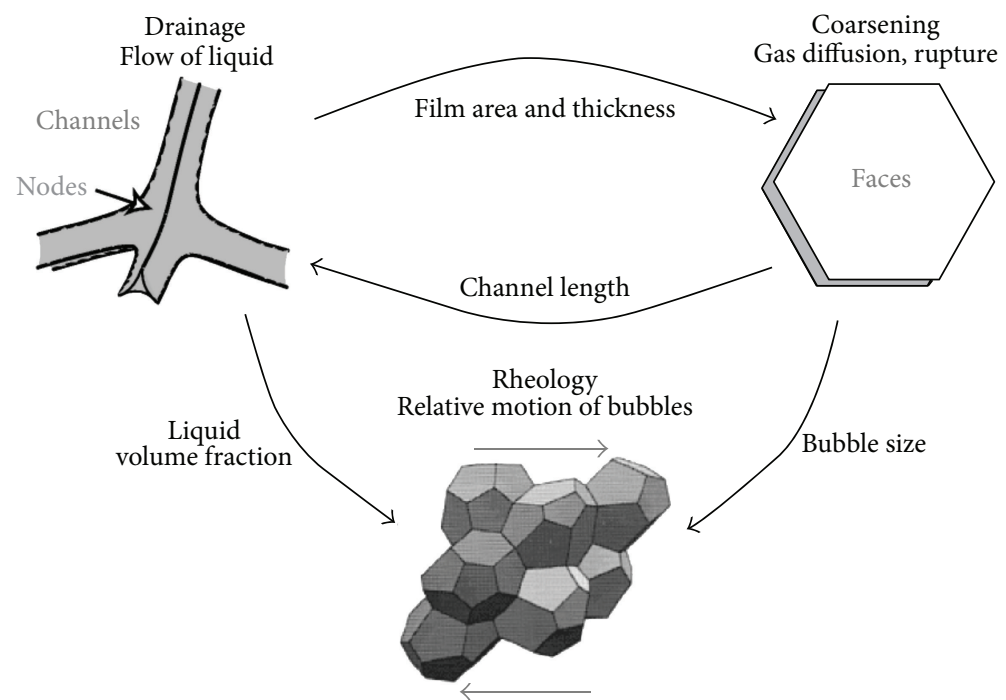

FIGURE 1: Schematic illustration of the interdependence of drainage, coarsening, and rheology of foams [3].

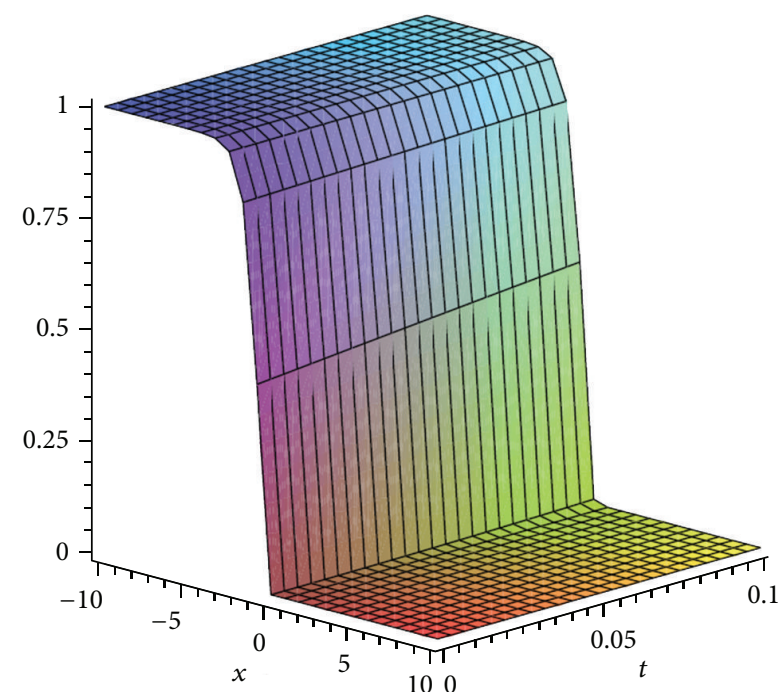

(a)

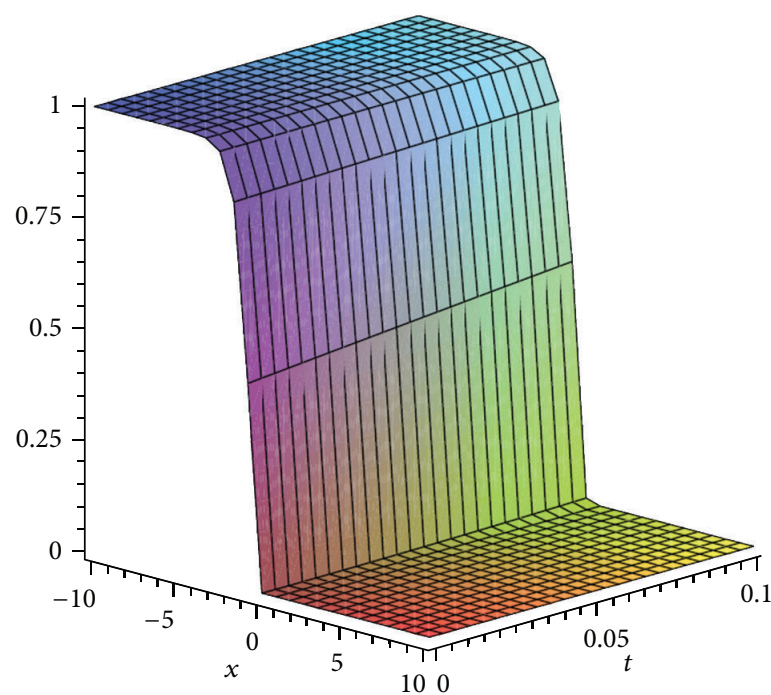

(b)

Figure 2: The surfaces on both columns, respectively, show the solutions, $u(x, t)$, for VIM-II on the right and exactly on the left when $c=1$.

familiar in tidal bores. Fadravi et al. [17] employed homotopy analysis method for solving foam drainage equation with space- and time-fractional derivatives. homotopy perturbation method was used for solving the foam drainage equation by Fereidoon et al. [18].

In recent years, several such techniques have drawn special attention, such as inverse scattering method [19], Adomian decomposition method [20,21], Hamiltonian approach [22], variational iteration method [23-25], homotopy analysis method [26, 27], variational approach [28], and homotopy perturbation method [29-38].

The aim of current study is to analytically investigate nonlinear foam drainage equation in the form of (1), using variational iteration method-II (VIM-II) $[39,40]$. We will apply new algorithm that is a powerful and efficient technique in finding the approximate solutions for the following foam drainage equation:

$$
\frac{\partial A}{\partial t}+\frac{\partial}{\partial x}\left(A^{2}-\frac{\sqrt{A}}{2} \frac{\partial A}{\partial x}\right)=0,
$$

where $x$ and $t$ are scaled position and time coordinates, respectively.

In the case of forced drainage, the solution can be expressed as [41]

$$
A(x, t)=c \tanh ^{2}(\sqrt{c}(x-c t)),
$$

where $c$ is the velocity of the wave front [16].

The pursuit of analytical solutions for foam drainage equation is of intrinsic scientific interest. To the best of 


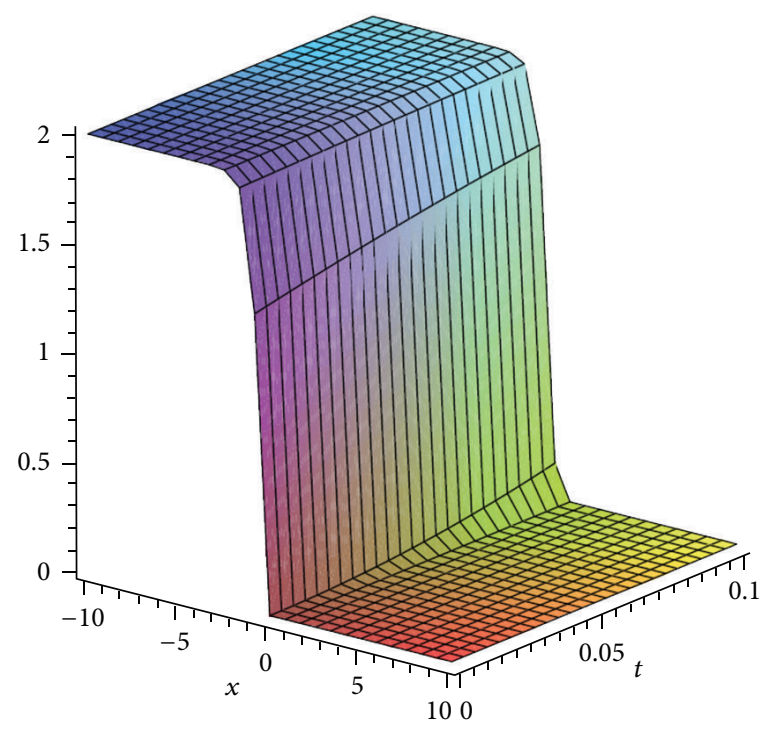

(a)

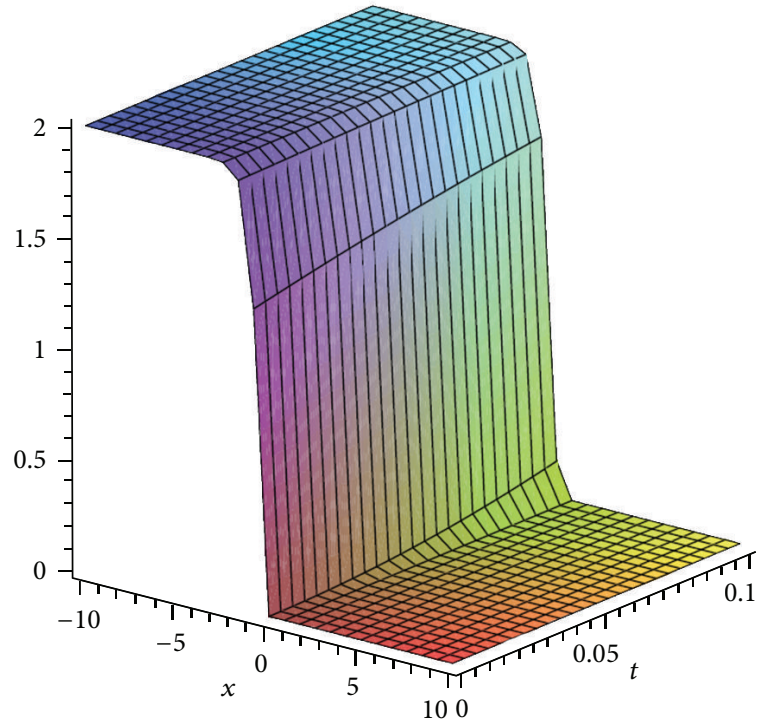

(b)

Figure 3: The surfaces on both columns, respectively, show the solutions, $u(x, t)$, for VIM-II on the right and exactly on the left when $c=2$.

the authors' knowledge, there is no paper that has solved the nonlinear foam drainage equation by VIM-II. In this paper, the basic idea of VIM-II is described, and then, it is applied to study the following nonlinear foam drainage equation. Finally, the results of VIM-II and HPM as analytical solutions are then compared with those derived from Adomian decomposition method.

\section{Basic Concept of VIM-II}

In the following section, to clarify the idea of the proposed method for solution of the nonlinear governing equation of a cantilever beam undergoing large deformation, the basic concept of variational iteration method-II $[39,40]$ is firstly treated. A general nonlinear equation of $k$ th order is considered at the following form:

$$
u^{(k)}+f\left(u^{\prime}+u^{\prime \prime}+\cdots+u^{(k)}\right)=0
$$

The classical variational iteration algorithm is as follows:

$$
u_{n+1}(t)=u_{n}(t)+\int_{0}^{t} \lambda\left(u_{n}^{(k)}+\widetilde{f}_{n}\right) d \varepsilon
$$

where $\lambda$ is a general Lagrange multiplier. We apply Laplace transform to identify the Lagrange multiplier [42-44]. By using Laplace transform, we have

$$
\begin{gathered}
s^{k} U(s)+\ell\left\{f\left(u, u^{\prime}, \ldots, u^{(k)}\right)\right\}=0, \\
U(s)=\frac{-\ell\left\{f\left(u, u^{\prime}, \ldots, u^{(k)}\right)\right\}}{s^{k}} .
\end{gathered}
$$

The inverse Laplace transform reads as

$$
u(t)=(-1)^{k} \int_{0}^{t} \frac{(\varepsilon-t)^{k-1}}{(k-1) !} f\left(u_{n}(\varepsilon), u_{n}^{\prime}(\varepsilon), \ldots, u_{n}^{(k)}(\varepsilon)\right) d \varepsilon .
$$

Hence, after identifying the Lagrange multiplier $\lambda$, the variational iteration algorithm-II $[39,40]$ is constructed as follows:

$$
\begin{aligned}
u_{n+1}(t)= & u_{0}(t)+(-1)^{k} \\
& \times \int_{0}^{t} \frac{(\varepsilon-t)^{k-1}}{(k-1) !} f\left(u_{n}(\varepsilon), u_{n}^{\prime}(\varepsilon), \ldots, u_{n}^{(k)}(\varepsilon)\right) d \varepsilon .
\end{aligned}
$$

The above equation is generally called the variational iteration algorithm-II, in which $u_{0}(t)$ is the initial solution. The initial values are usually used for selecting the zeroth approximation $u_{0}$. With $u_{0}$ determined, then several approximations $u_{n} n>$ 0 , follow immediately. Consequently, the exact solution could be obtained as follows:

$$
u(t)=\lim _{n \rightarrow \infty} u_{n} .
$$

\section{Implementation of VIM-II}

In this section, we will apply the VIM-II to solve foam drainage equation. Foam drainage equation (1) can be written as [41]:

$$
u_{t}+2 u u_{x}-\frac{\sqrt{u}}{2} u_{x x}-\frac{1}{4 \sqrt{u}}\left(u_{x}\right)^{2}=0,
$$

with initial conditions

$$
u(x, 0)=3 \tanh ^{2}(\sqrt{3} x) .
$$


TABLE 1: Comparison between errors of ADM, HPM, and VIM-II for $t=0.01$ and $c=3$.

\begin{tabular}{lccc}
\hline$X$ & $u_{\text {exact }}-u_{\mathrm{HPM}}$ & $u_{\text {exact }}-u_{\mathrm{ADM}}$ & $u_{\text {exact }}-u_{\mathrm{VIM}-\mathrm{II}}$ \\
\hline-10 & $2.4 E-18$ & $1.77636 E-15$ & 0 \\
-8 & $2.01600 E-15$ & $1.86962 E-12$ & 0 \\
-6 & $2.05744 E-12$ & $1.9087 E-9$ & 0 \\
-4 & $2.09993 E-9$ & $1.94811 E-6$ & $6 E-08$ \\
-2 & 0.000002123 & 0.00197296 & $-6.0881 E-0.5$ \\
-1 & 0.000050433 & 0.0485679 & 0 \\
0 & 0.000014557 & 0.00051592 & $8.08544 E-3$ \\
\hline
\end{tabular}

TABLE 2: Comparison between errors of ADM, HPM, and VIM-II for $t=0.001$ and $c=3$.

\begin{tabular}{lccc}
\hline$X$ & $u_{\text {exact }}-u_{\mathrm{HPM}}$ & $u_{\text {exact }}-u_{\mathrm{ADM}}$ & $u_{\text {exact }}-u_{\mathrm{VIM}-\mathrm{II}}$ \\
\hline-10 & 0 & $4.44089 E-16$ & 0 \\
-8 & $2.4 E-18$ & $2.24265 E-13$ & 0 \\
-6 & $2.1059 E-15$ & $2.29754 E-10$ & 0 \\
-4 & $2.14918 E-12$ & $2.34498 E-7$ & 0 \\
-2 & $2.17229 E-9$ & 0.000236656 & $3.54069 E-15$ \\
-1 & $5.10302 E-8$ & 0.00523834 & $1.64365 E-13$ \\
0 & $1.45797 E-9$ & $5.2479 E-8$ & 0 \\
\hline
\end{tabular}

The exact solution for this problem is

$$
u(x, t)=c \tanh ^{2}(\sqrt{c}(x-c t)) .
$$

The VIM-II is implemented in (9). First, according to the method, by applying Laplace transform to identify the Lagrange multiplier, we have

$$
\lambda=1 \text {. }
$$

So, variational iteration algorithm-II is derived:

$$
u_{n+1}=u_{0}+\int_{0}^{t}\left(-2 u u_{x}+\frac{\sqrt{u}}{2} u_{x x}+\frac{1}{4 \sqrt{u}}\left(u_{x}\right)^{2}\right) d \varepsilon
$$

According to the above equation, for first order approximation, it can be written as follows:

$$
u_{1}=u_{0}+\int_{0}^{t}\left(-2 u_{0} u_{0 x}+\frac{\sqrt{u_{0}}}{2} u_{0 x x}+\frac{1}{4 \sqrt{u_{0}}}\left(u_{0 x}\right)^{2}\right) d \varepsilon .
$$

We have the following successive approximation:

$$
\begin{aligned}
u_{1}= & 3 \tanh (\sqrt{3} x)^{2}-36 \tanh (\sqrt{3} x)^{3} \\
& \times\left(1-\tanh (\sqrt{3} x)^{2}\right) \sqrt{3} t \\
& +\frac{\sqrt{3}}{2} \sqrt{\tanh (\sqrt{3} x)^{2}} \times 18\left(1-\tanh (\sqrt{3} x)^{2}\right)^{2} \\
& -36 \tanh (\sqrt{3} x)^{2}\left(1-\tanh (\sqrt{3} x)^{2}\right) t \\
& +\frac{9 \tanh (\sqrt{3} x)^{2}\left(1-\tanh (\sqrt{3} x)^{2}\right)^{2} \sqrt{3} t}{\sqrt{\tanh (\sqrt{3} x)^{2}}} .
\end{aligned}
$$

Proceeding in the same way, we can obtain the high order approximations. The VIM-II method admits the use of

$$
u=\lim _{n \rightarrow \infty} u_{n}
$$

By Figures 2 and 3, we may simply compare the VIM-II solution and exact solution of (1) for $c=1$ and $c=2$, respectively. Tables 1 and 2 investigated comparison presented method and HPM [18] between errors of ADM [41].

\section{Conclusions}

In this paper, an explicit analytical solution is obtained for foam drainage equation by means of the variational iteration method-II (VIM-II), which is a powerful mathematical tool in dealing with nonlinear equations. By looking at the results of figures and tables, we can see that the agreement between VIM-II and Adomian decomposition method (ADM) is satisfactory. Clearly, VIM-II is easy to calculate with the explicit polynomial expressions. This is especially convenient for practical engineering applications with minimum requirements on calculation and computation.

\section{Conflict of Interests}

The author declares that there is no conflict of interests regarding the publication of this paper.

\section{References}

[1] J. J. Bikerman, Foams, Springer, New York, NY, USA, 1973.

[2] R. K. Prud'homme and S. A. Khan, Eds., Foams: Theory, Measurements and Applications, Marcel Dekker, New York, NY, USA, 1996.

[3] S. Hilgenfeldt, S. A. Koehler, and H. A. Stone, "Dynamics of coarsening foams: accelerated and self-limiting drainage," Physical Review Letters, vol. 86, no. 20, pp. 4704-4707, 2001.

[4] S. D. Stoyanov, V. N. Paunov, E. S. Basheva, I. B. Ivanov, A. Mehreteab, and G. Broze, "Motion of the front between thick and thin film: hydrodynamic theory and experiment with vertical foam films," Langmuir, vol. 13, no. 6, pp. 1400-1407, 1997.

[5] H. A. Stone, S. A. Koehler, S. Hilgenfeldt, and M. Durand, "Perspectives on foam drainage and the influence of interfacial rheology," Journal of Physics Condensed Matter, vol. 15, no. 1, pp. S283-S290, 2003.

[6] J. I. B. Wilson, "Essay review, scholarly froth and engineering skeletons," Contemporary Physics, vol. 44, pp. 153-155, 2003.

[7] L. J. Gibson and M. F. Ashby, Cellular Solids: Structure and Properties, Cambridge University Press, Cambridge, UK, 1997.

[8] J. Banhart, Metallschaume, MIT-Verlag, Bermen, Canada, 1997.

[9] S. A. Koehler, H. A. Stone, M. P. Brenner, and J. Eggers, "Dynamics of foam drainage," Physical Review E, vol. 58, no. 2, pp. 20972106, 1998.

[10] M. Durand and D. Langevin, "Physicochemical approach to the theory of foam drainage," European Physical Journal E, vol. 7, no. 1, pp. 35-44, 2002.

[11] R. A. Leonard and R. Lemlich, "A study of interstitial liquid flow in foam. Part I: theoretical model and application to foam fractionation," AIChE Journal, vol. 11, no. 1, pp. 18-25, 1965. 
[12] I. I. Gol'dfarb, K. B. Kann, and I. R. Shreiber, "Liquid flow in foams," Fluid Dynamics, vol. 23, no. 2, pp. 244-249, 1988.

[13] D. Weaire and S. Hutzler, The Physics of Foams, Oxford University Press, Oxford, UK, 2000.

[14] G. Verbist and D. Weaire, "Soluble model for foam drainage," Europhysics Letters, vol. 26, pp. 631-634, 1994.

[15] G. Verbist, D. Weaire, and A. M. Kraynik, "The foam drainage equation," Journal of Physics Condensed Matter, vol. 8, no. 21, pp. 3715-3731, 1996.

[16] G. Verbist and D. Weaire, "A soluble model for foam drainage," Europhysics Letters, vol. 26, no. 8, article 631, 1994.

[17] H. H. Fadravi, H. Saberi Nik, and R. Buzhabadi, "Homotopy analysis method for solving foam drainage equation with spaceand time-fractional derivatives," International Journal of Differential Equations, vol. 2011, Article ID 237045, 12 pages, 2011.

[18] A. Fereidoon, H. Yaghoobi, and M. Davoudabadi, "Application of the homotopy perturbation method for solving the foam drainage equation," International Journal of Differential Equations, vol. 2011, Article ID 864023, 13 pages, 2011.

[19] V. O. Vakhnenko, E. J. Parkes, and A. J. Morrison, "A Bäcklund transformation and the inverse scattering transform method for the generalised Vakhnenko equation," Chaos, Solitons and Fractals, vol. 17, no. 4, pp. 683-692, 2003.

[20] G. Adomian, "Nonlinear dissipative wave equations," Applied Mathematics Letters, vol. 11, no. 3, pp. 125-126, 1998.

[21] S. Abbasbandy, "A numerical solution of Blasius equation by Adomian's decomposition method and comparison with homotopy perturbation method," Chaos, Solitons and Fractals, vol. 31, no. 1, pp. 257-260, 2007.

[22] R. Taghipour, T. Akhlaghi, and A. Nikkar, "Explicit solution of the large amplitude transverse vibrations of a flexible string under constant tension," Latin American Journalof Solids and Structures, vol. 11, no. 3, pp. 545-555, 2014.

[23] A. Barari, H. D. Kaliji, M. Ghadim, and G. Domairry, "Non-linear vibration of Euler-Bernoulli beams," Latin American Journal of Solids and Structures, vol. 8, no. 2, pp. 139-148, 2011.

[24] S. Saedodin, H. Yaghoobi, and M. Torabi, "Application of the variational iteration method to nonlinear non-Fourier conduction heat transfer equation with variable coefficient," Heat Transfer, vol. 40, no. 6, pp. 513-523, 2011.

[25] P. Salehi, H. Yaghoobi, and M. Torabi, "Application of the differential transformation method and variational iteration method to large deformation of cantilever beams under point load," Journal of Mechanical Science and Technology, vol. 26, no. 9, pp. 2879-2887, 2012.

[26] H. Jafari, C. Chun, S. Seifi, and M. Saeidy, "Analytical solution for nonlinear gas dynamic equation by homotopy analysis method," Applications and Applied Mathematics, vol. 4, no. 1, pp. 149-154, 2009.

[27] Y. Khan, R. Taghipour, M. Falahian, and A. Nikkar, "A new approach to modified regularized long wave equation," Neural Computing and Applications, vol. 23, pp. 1335-1341, 2013.

[28] S. Bagheri, A. Nikkar, and H. Ghaffarzadeh, "Study of nonlinear vibration of Euler-Bernoulli beams by using analytical approximate techniques," Latin American Journal of Solids and Structures, vol. 11, no. 1, pp. 157-168, 2014.

[29] J.-H. He, "Coupling method of a homotopy technique and a perturbation technique for non-linear problems," International Journal of Non-Linear Mechanics, vol. 35, no. 1, pp. 37-43, 2000.

[30] J.-H. He, "Addendum: new interpretation of homotopy perturbation method," International Journal of Modern Physics B, vol. 20, no. 18, pp. 2561-2568, 2006.
[31] J. H. He, "Recent development of the homotopy perturbation method," Topological Methods in Nonlinear Analysis, vol. 31, no. 2, pp. 205-209, 2008.

[32] J.-H. He, "The homotopy perturbation method for nonlinear oscillators with discontinuities," Applied Mathematics and Computation, vol. 151, no. 1, pp. 287-292, 2004.

[33] J.-H. He, "Application of homotopy perturbation method to nonlinear wave equations," Chaos, Solitons and Fractals, vol. 26, no. 3, pp. 695-700, 2005.

[34] J.-H. He, "Limit cycle and bifurcation of nonlinear problems," Chaos, Solitons and Fractals, vol. 26, no. 3, pp. 827-833, 2005.

[35] H. Aminikhah, F. Mehrdoust, and A. Jamalian, "A new efficient method for nonlinear Fisher-type equations," Journal of Applied Mathematics, vol. 2012, Article ID 586454, 18 pages, 2012.

[36] H. Aminikhah and A. Jamalian, "A new efficient method for solving the nonlinear Fokker-Planck equation," Scientia Iranica, vol. 19, pp. 1133-1139, 2012.

[37] H. Aminikhah and M. Hemmatnezhad, "An efficient method for quadratic Riccati differential equation," Communications in Nonlinear Science and Numerical Simulation, vol. 15, no. 4, pp. 835-839, 2010.

[38] H. Aminikhah and A. Jamalian, "Numerical approximation for nonlinear gas dynamic equation," International Journal of Partial Differential Equations, vol. 2013, Article ID 846749, 7 pages, 2013.

[39] J. H. He, "Asymptotic methods for solitary solutions a compactons," Abstract and Applied Analysis, vol. 2012, Article ID 916793, 130 pages, 2012.

[40] H. Ghaffarzadeh and A. Nikkar, "Explicit solution to the large deformation of a cantilever beam under point load at the free tip using the variational iteration method-II," Journal of Mechanical Science and Technology, vol. 27, no. 11, pp. 3433-3438, 2013.

[41] M. A. Helal and M. S. Mehanna, "The tanh method and Adomian decomposition method for solving the foam drainage equation," Applied Mathematics and Computation, vol. 190, no. 1, pp. 599-609, 2007.

[42] E. Hesameddini and H. Latifizadeh, "Reconstruction of variational iteration algorithms using the laplace transform," International Journal of Nonlinear Sciences and Numerical Simulation, vol. 10, no. 11-12, pp. 1377-1382, 2009.

[43] A. Nikkar, Z. Mighani, S. M. Saghebian, S. B. Nojabaei, and M. Daie, "Development and validation of an analytical method to the solution of modelling the pollution of a system of lakes," Research Journal of Applied Sciences, Engineering and Technology, vol. 5, no. 1, pp. 296-302, 2013.

[44] S. Ghasempour, J. Vahidi, A. Nikkar, and M. Mighani, "Analytical approach to some highly nonlinear equations by means of the RVIM," Research Journal of Applied Sciences, Engineering and Technology, vol. 5, no. 1, pp. 339-345, 2013. 


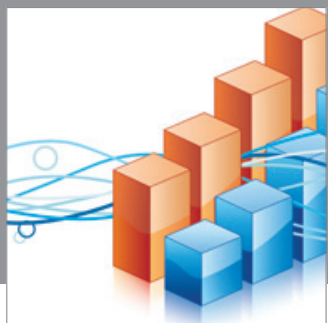

Advances in

Operations Research

mansans

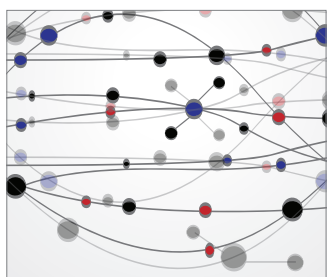

The Scientific World Journal
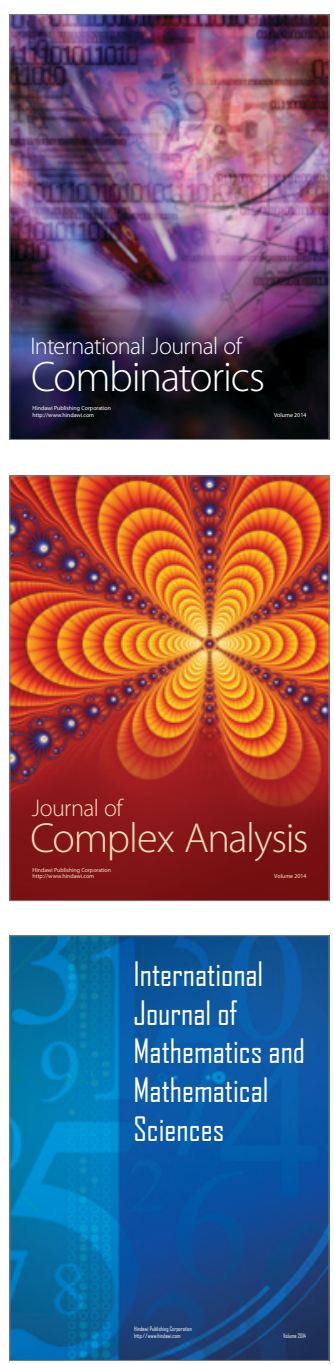
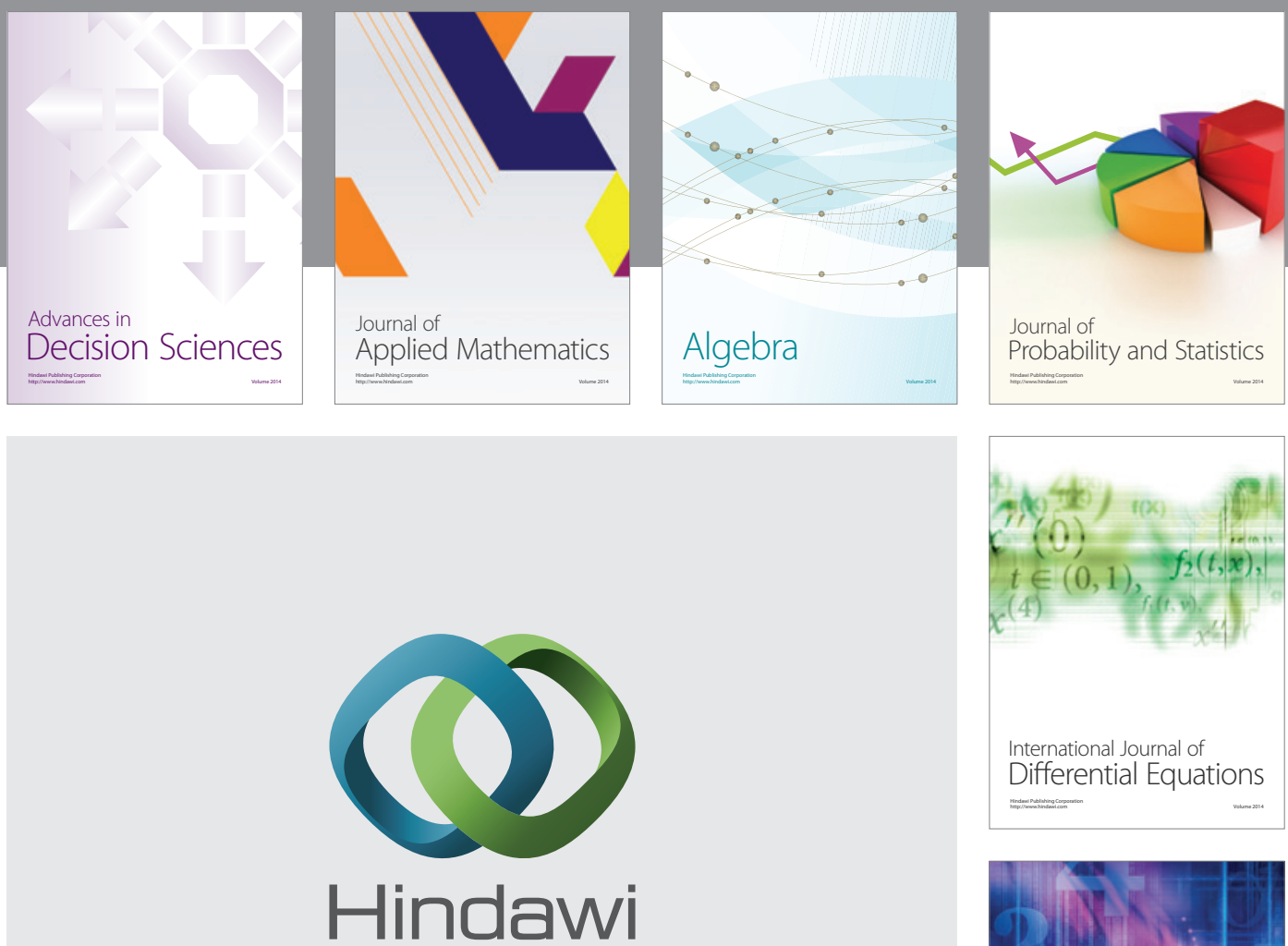

Submit your manuscripts at http://www.hindawi.com
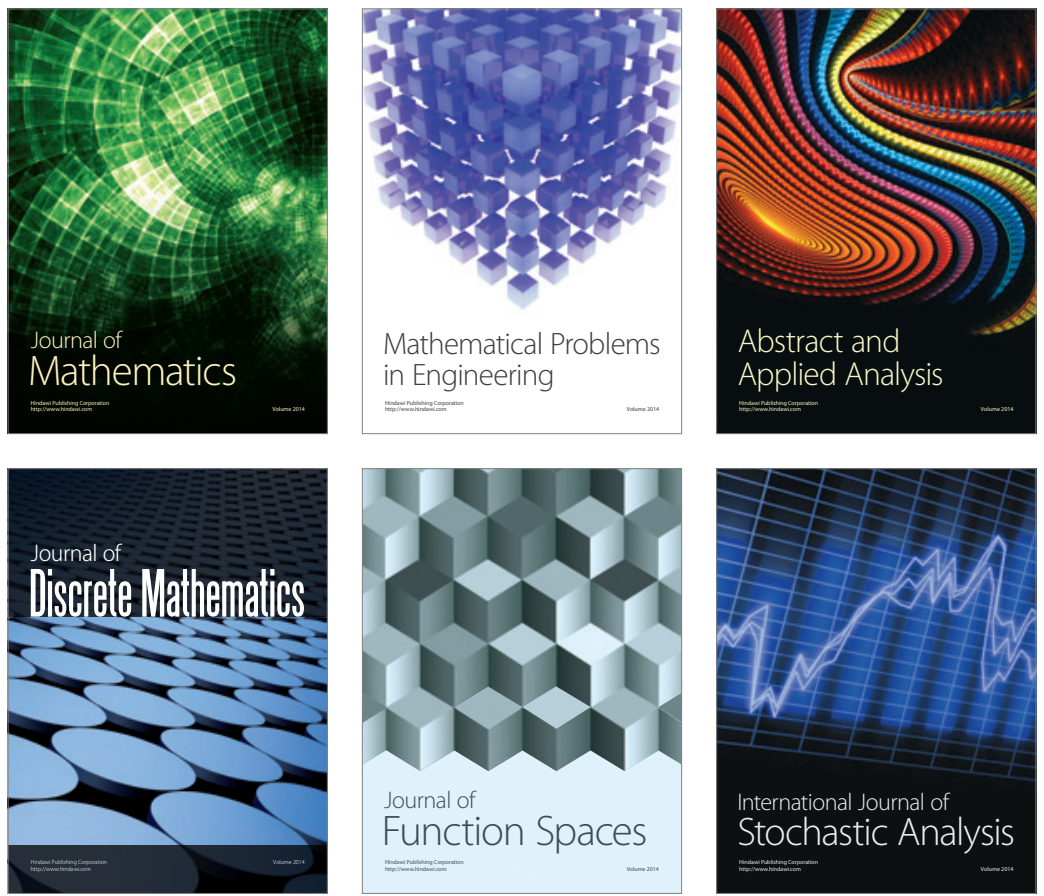

Journal of

Function Spaces

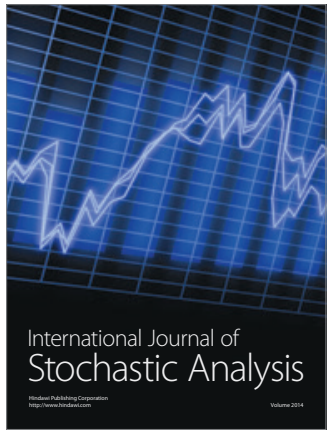

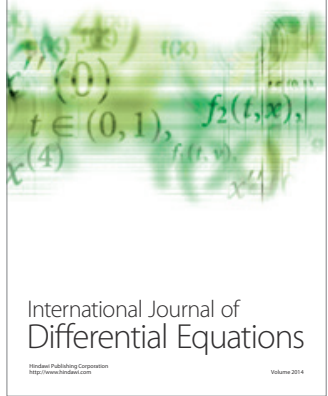
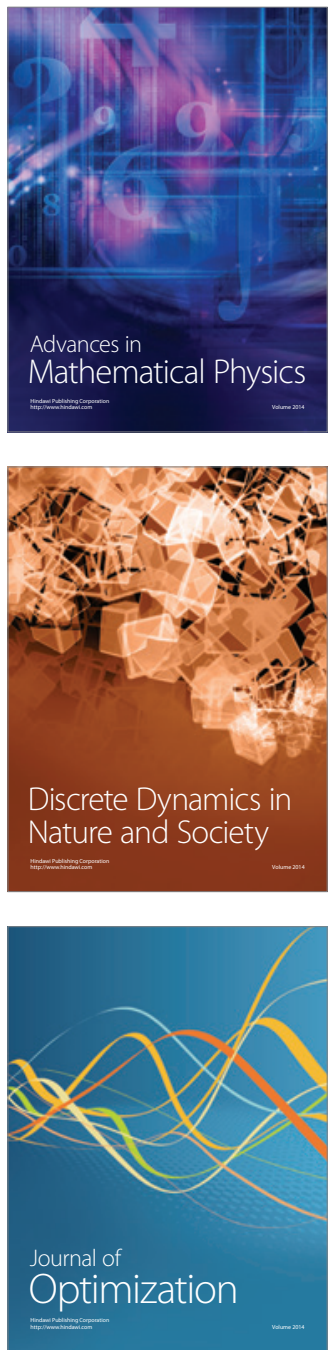